\title{
Color Prediction of Yarn-dyed Woven Fabrics -Model Evaluation-
}

\author{
Youngjoo Chae $\cdot$ John $\mathrm{Xin}^{\dagger} \cdot$ Tao Hua \\ The Institute of Textiles \& Clothing, The Hong Kong Polytechnic University \\ Received December 4, 2013; Revised April 24, 2014, Accepted May 14, 2014
}

\begin{abstract}
The color appearance of a yarn-dyed woven fabric depends on the color of the yarn as well as on the weave structure. Predicting the final color appearance or formulating the recipe is a difficult task, considering the interference of colored yarns and structure variations. In a modern fabric design process, the intended color appearance is attained through a digital color methodology based on numerous color data and color mixing recipes (i.e., color prediction models, accumulated in CAD systems). For successful color reproduction, accurate color prediction models should be devised and equipped for the systems. In this study, the final colors of yarn-dyed woven fabrics were predicted using six geometric-color mixing models (i.e., simple $K / S$ model, log $K / S$ model, D-G model, S-N model, modified S-N model, and W-O model). The color differences between the measured and the predicted colors were calculated to evaluate the accuracy of various color models used for different weave structures. The $\log K / S$ model, D-G model, and W-O model were found to be more accurate in color prediction of the woven fabrics used. Among these three models, the W-O model was found to be the best one as it gave the least color difference between the measured and the predicted colors.
\end{abstract}

Key words: Color prediction, Color appearance, Color mixing model, Model evaluation, Yarn-dyed woven fabric

\section{Introduction}

Color is one of the most important aspects for woven fabric design. In order to produce a desired color, color mixing should be performed. Color mixing in woven fabrics is defined as the process of combining a series of differently colored yarns in varying proportions to obtain one overall color appearance (Mathur, 2007; Seyam \& Mathur, 2012). In modern fabric design process, the intended color appearance is achieved through a digital color mixing methodology providing simulation of the final appearance of actual

${ }^{\dagger}$ Corresponding author

E-mail: john.xin@polyu.edu.hk

This research was supported by the Research Grants Council (RGC) under the Hong Kong PhD Fellowship Scheme. fabrics based on the color mixing recipes accumulated in CAD systems. In order to achieve successful color reproduction through the accurate color prediction result of the simulation and thereby reduced unnecessary physical sampling prior to production, the systems require more reliable color mixing models.

A number of color mixing models have been developed to predict the final color of texiles, especially fiber blends (Burlone, 1984; Philips-Invernizzi et al., 2002; Reed et al., 2004; Stearns \& Noechel, 1944; Warburton \& Oliver, 1956). However, there have been few studies (Dimitrovski \& Gabrijelcic, 2004; Mathur, 2007; Mathur et al., 2009) reported on the color prediction of yarn-dyed woven fabrics or the application of previous color models to woven fabrics. In the previous study on the model evaluation for woven fab- 
rics (Mathur et al., 2009), only three color mixing models, i.e., simple $K / S, \log K / S$, and D-G models, were tested, and among those, a $\log K / S$ model was the best one with the least average error between the predicted and actual colors.

This study was carried out to evaluate the accuracy and possible applicability of various color prediction models, including those that have never been tested before, to yarn-dyed woven fabrics. To attain this goal, the color attributes of 10 woven fabrics produced were predicted by using six color mixing models. Then, the color differences between the measured and the predicted colors were calculated. Finally, the color differences calculated by each model were compared to decide the most appropriate model to be used for woven structures.

\section{Color Prediction Method for Woven Fabrics}

According to previous studies (Mathur, 2007; Mathur et al., 2009), the final color attributes of yarn-dyed woven fabrics can be predicted according to two steps. Firstly, each color proportion on the fabric surface is calculated based on four geometric parameters: warp yarn diameter $\left(d_{w}\right)$, weft yarn diameter $\left(d_{f}\right)$, warp spacing $\left(s_{w}\right)$, and weft spacing $\left(s_{f}\right)$. In the second step, based on each color proportion obtained, the final color attributes of fabrics are predicted by using color mixing models.

\section{Geometric Calculation}

For the calculation of each color proportion, the following assumptions are made: yarns are uniformly colored cylinders, all warp spacing are of same value, all weft spacing are of same value, and a woven structure has a two-dimensional flat surface (Mathur, 2007). In this study, based on the above assumptions, geometric models $<$ Eq. $1>-<$ Eq. $3>$ were developed for woven fabrics composed of each single color of warp and weft yarns, thereby having three color portions, warp, weft, and background colors as shown in $<$ Fig. $1>$. The three color proportions are calculated as the covered area by each color divided by the total surface area of the fabric as follows:

$$
\begin{aligned}
& C_{w}= \\
& \frac{W F N\left(d_{w} \times s_{f}\right)+[(W N \times F N)-W F N] d_{w}\left(s_{f}-d_{f}\right)}{W N_{S w} \times F N_{S f}} \times 100 \\
& C_{f}=\quad \cdots . . \text { Eq. } 1 . \\
& \frac{F F N\left(d_{f} \times S_{w}\right)+[(W N \times F N)-F F N] d_{f}\left(s_{w}-d_{w}\right)}{W N_{S w} \times F N_{S f}} \times 100 \\
& C_{b}=100-\left(C_{w}+C_{f}\right) \\
& \text { Eq. } 2 .
\end{aligned}
$$

Where:

$C_{w}, C_{f}, C_{b}=$ proportion of warp color, weft color, and background color, respectively
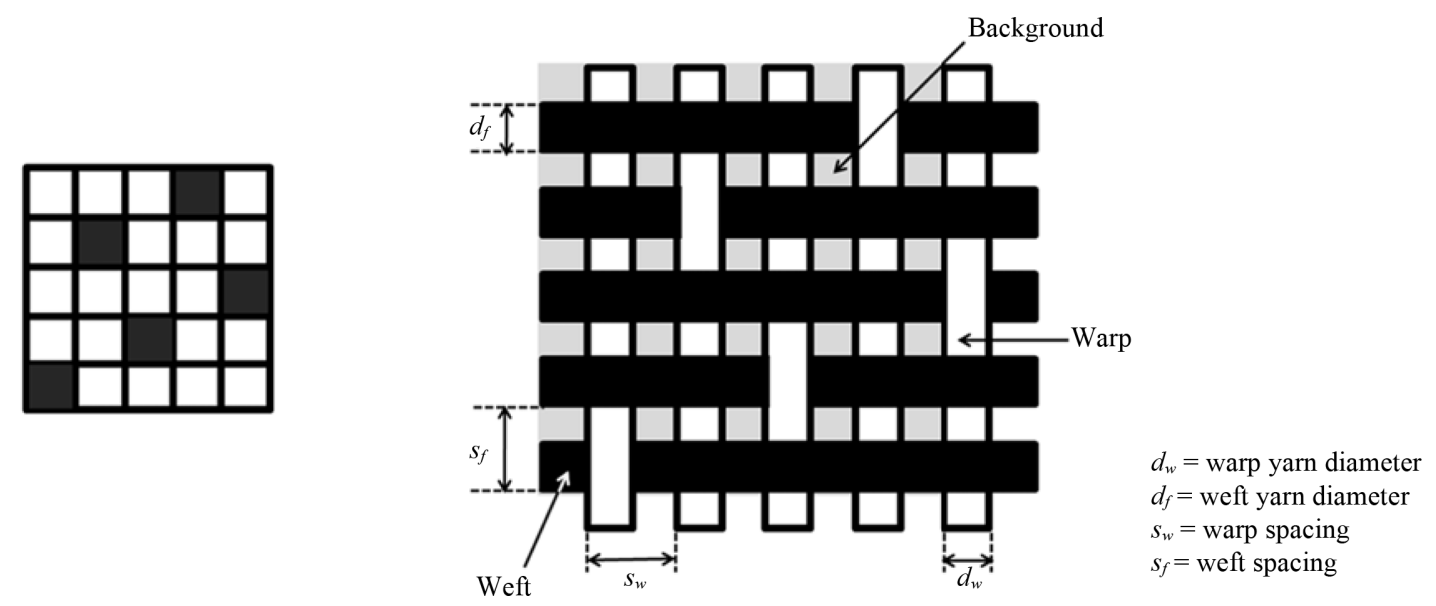

Fig. 1. An example of a weave design (left) and its two-dimensional projection (right) for geometric calculations. 
$W N, F N=$ number of warp yarns and weft yarns in a repeat, respectively

$W F N, F F N=$ number of warp floats and weft floats in a repeat, respectively

\section{Colorimetric Calculation}

The obtained color proportions and color attributes of yarns are then used in color mixing models. A number of color mixing models have been developed by several researchers:

A Simple Kubelka-Munk model $(K / S$ model $)$ is widely used for the colorant formulation in textile dyeing. The final color strength ratio, $K / S$ value (where, $K$ is absorption coefficient and $S$ is scattering coefficient), of a colored sample, i.e., $(K / S)_{\text {mix }}$, is an additive combination of individual $(K / S)$ values for each colorant used as described in $<$ Eq. $4>$ (Mathur, 2007):

$$
(K / S)_{\text {mix }}=(K / S)_{\text {sub }}+(K / S)_{1}+(K / S)_{2}+\ldots+(K / S)_{\mathrm{n}}
$$

Where,

$(K / S)_{\text {mix }}=(K / S)$ value of the mixture

$(K / S)_{\text {sub }}=(K / S)$ value of the substrate

$(K / S)_{1-\mathrm{n}}=(K / S)$ value of each colorant

By a recent review (Burlone, 1984), Stearns \& Noechel model (Stearns \& Noechel, 1944) described in $<$ Eq. $5>-<$ Eq. $6>$ was found to produce more accurate results for color prediction of fiber blends than simple $K / S$ model. This model predicts the final reflectance value of a fiber blend from the individual reflectance values of each color component used. In $<$ Eq. $6>, b$ is an empirical constant of which value is determined experimentally.

$$
f\left[R_{\mathrm{blend}}(\lambda)\right]=\sum_{i} x_{i} \cdot f\left[R_{i}(\lambda)\right]
$$

Where,

$R_{\text {blend }}(\lambda), R_{i}(\lambda)=$ reflectance values of the blend and $i$ th component at wavelength $\lambda$, respectively

$x_{i}=$ proportion of $i$ th component in the blend

$f=$ additive function provided by the authors as follows:

$$
f[R(\lambda)]=\frac{1-R(\lambda)}{b \cdot[R(\lambda)-0.01]+0.01} \quad \cdots . . \text { Eq. } 6 .
$$

In, Philips-Invernizzi et al. (2002) found an effective way of computing $b$ and came up with a new model $<$ Eq. $7>-<$ Eq. $8>$ which can advantageously replace the original Stearns-Noechel model.

$$
\varphi\left[R_{\text {blend }}(\lambda)\right]=\sum_{i} x_{i} \cdot \varphi\left[R_{i}(\lambda)\right] \quad \cdots . . \text { Eq. } 7 .
$$

Where $R_{\text {blend }}(\lambda), R_{i}(\lambda)$ and $x_{i}$ are the same as those previously defined in $\langle$ Eq. 5$\rangle$, and $\varphi$ is the additive function newly provided by the authors as follows:

$$
\varphi[R(\lambda)]=\frac{1000 \cdot[1-R(\lambda)]}{(0.12 \cdot \lambda+42.75) \cdot[R(\lambda)-0.01]+0.01}
$$

Reed et al. (2004) studied the mixing effect of colored fibers by using uniformly distributed fibers in non-woven hydro-entangled polyester fabrics. Based on the result of their experiment, they came up with a modified $K / S$ mixing theory, a log-based $K / S$ model, for the additive law of colors as described in $\langle$ Eq. $9>$.

$$
\log (K / S)_{\lambda_{\text {mix }}}=\sum_{i=1}^{n} c_{i} \log (K / S)_{\lambda_{\mathrm{i}}} \quad \quad \cdots . . \text { Eq. } 9 .
$$

Where,

$(K / S)_{\text {mix }},(K / S)_{\mathrm{i}}=(K / S)$ values of the mixture and $i$ th color, respectively

$$
c_{i}=\text { proportion of } i \text { th color in the mixture }
$$

Dimitrovski and Gabrijelcic (2004) suggested a method for calculating the color attributes of woven fabrics from the known color attributes of individual yarns used. Theoretical calculations of color attributes of woven fabrics made of single colored warp and weft yarns were reported as given in $<$ Eq. $10>-<$ Eq. $12>$.

$$
\begin{array}{ll}
L^{*}=\left(L^{*}{ }_{w} c_{w}\right)+\left(L_{f}^{*} c_{f}\right)+\left(L^{*}{ }_{b} c_{b}\right) & \cdots . . \text { Eq. } 10 . \\
a^{*}=\left(a^{*}{ }_{w}{ }_{w}\right)+\left(a_{f}^{*} c_{f}\right)+\left(a^{*}{ }_{b} c_{b}\right) & \ldots . . \text { Eq. } 11 . \\
b^{*}=\left(b^{*}{ }_{w} c_{w}\right)+\left(b^{*}{ }_{f} c_{f}\right)+\left(b^{*}{ }_{b} c_{b}\right) & \cdots . . \text { Eq. } 12 .
\end{array}
$$

Where,

$c_{w}, c_{f}, c_{b}=$ proportions of warp, weft, and background colors, respectively

$L^{*}{ }_{w}, L^{*}, L^{*}{ }_{b}=$ lightness values of warp, weft, and 
background colors, respectively

$a^{*}, a_{f}^{*}, a_{b}^{*}=$ redness-greenness values of warp, weft, and background colors, respectively

$b^{*}, b_{f}^{*}, b_{b}^{*}=$ blueness-yellowness values of warp, weft, and background colors, respectively

Warburton and Oliver (1956) investigated the color combination effect of blended fibers and devised a new color mixing model predicting the reflectance of blends, described in $\langle$ Eq. 13 $>$. The derived model was based on the theory of light passing through two colored filters successively, where $R$ and $R_{\mathrm{i}}$ have replaced the transmitted intensities of unit thickness of filters and ${ }^{x}$ and ${ }^{1-x}$ are the respective thickness of the successive filters, having unit thickness taken together.

$$
R=R_{1}^{x} R_{2}^{1-x}
$$

Where,

$R, R_{\mathrm{i}}=$ reflectance values of the blend and $i$ th component, respectively

${ }^{x, 1-x}=$ proportions of each component

\section{Methods}

\section{Samples}

10 woven fabrics of different color combinations of warp and weft yarns and weave structures were constructed using a LX3202 Staubli jacquard machine. White yarns were used for warp for all the samples, and red and blue yarns, two basic colored yarns commonly used in color mixing for woven structures, were used respectively for weft $(\mathrm{W} \times \mathrm{R} / \mathrm{W} \times \mathrm{B})$. Five different weaves, including $1 / 1$ plain, $1 / 2$ twill, $2 / 1$ twill, $1 / 4$ sateen and $4 / 1$ satin, were used. All the yarns used were semi-lustrous polyester filament yarns, and the yarn diameter and fabric density were $0.125 \mathrm{~mm}$ and $47 \times 30 / \mathrm{cm}$, respectively.

\section{Instrumental Color Measurement}

The spectral reflectance values of three yarns, 10 fabrics, and a calibration tile which was used as background were measured using a Macbeth Color-Eye $7000 \mathrm{~A}$ spectrophotometer with the following specifi- cations: diffuse $/ 8^{\circ}$ geometry, specular excluded, UV excluded, and large area view. In case of yarns, the colors were measured in the form of being evenly wound in at eight layers onto nonfluorescent cardboard for consistent reflectance measurement. The measured reflectance data were converted into $K / S$, $\mathrm{L}^{*}, \mathrm{a}^{*}, \mathrm{~b}^{*}, \mathrm{C}^{*}$, and $\mathrm{h}^{\mathrm{o}}$ values using CIE $10^{\circ}$ standard observer and illuminant D65.

\section{Color Prediction}

Color proportions, i.e. fractions of individual colors in a weave repeat, of warp and weft yarns and background were calculated by $<$ Eq. $1>-<$ Eq. $3>$ first. Then, the final color attributes of 10 fabrics were predicted by six color mixing models: simple $K / S$ model $<$ Eq. $4>, \log K / S$ model $<$ Eq. $9>$, D-G model $<$ Eq. $1>-<$ Eq. 12 $>$, S-N model $<$ Eq. $5>-<$ Eq. $6>$, modified S-N model $<$ Eq. $7>-<$ Eq. $8>$, and W-O model (Eq. 13). The procedure to predict the final color attributes of fabrics from the reflectance and $K / S$ data of each yarn and background used is shown in $<$ Fig. $2>$. The predicted color attributes were then compared to the measured values by calculating the color difference, $\Delta \mathrm{E}_{\mathrm{CMC}(2: 1) \text {. }}$

\section{Results and Discussion}

Calculated color proportions of warp and weft yarns and background for each weave structure are given in $<$ Table $1>$. Based on these data, predicted colorimetric values of red woven fabrics by six color mixing models are shown as an example in $<$ Table $2>$. The colorimetric values of actual fabrics shown in $\langle$ Table $2>$ were taken as standard and compared to the predicted values using $\mathrm{CMC}(2: 1)$ color difference formula.

As presented in $<$ Fig. $3>$, $\log K / S$ model, D-G model, and $\mathrm{W}-\mathrm{O}$ model were relatively accurate in prediction of the final colors of the woven fabrics used. Among them, W-O model was the most accurate one with the least color difference between the measured and the predicted colors.

From $<$ Fig. $3>$, it can be seen that $\log K / S$ model produced significantly lower $\Delta \mathrm{E}_{\mathrm{CMC}(2: 1)}$ values than those of the Simple $K / S$ model and modified S-N mo- 


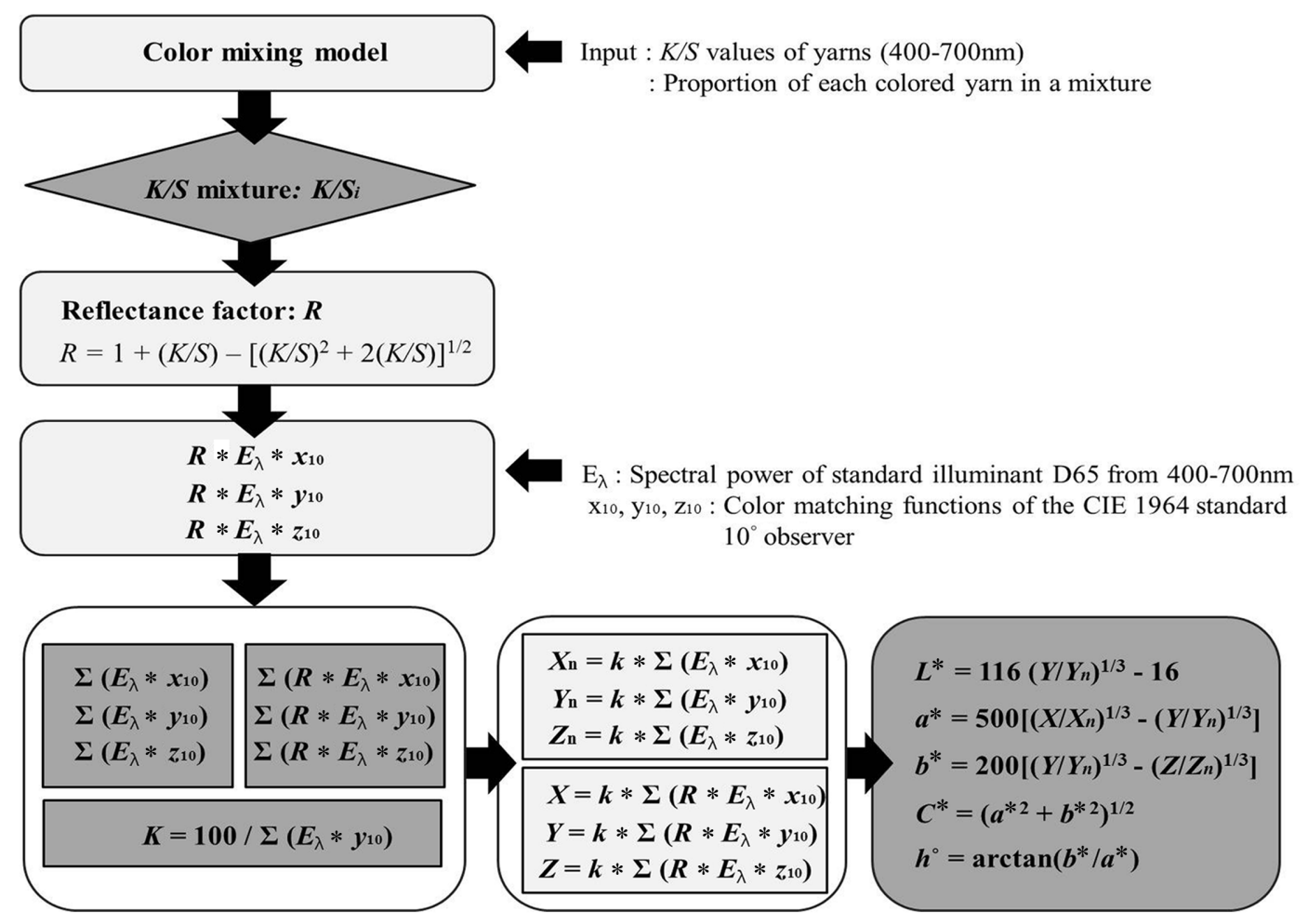

Fig. 2. Procedure for colorimetric calculations.

Table 1. Predicted color proportions of warp and weft yarns and background

\begin{tabular}{c|c|c|c}
\hline \hline \multirow{2}{*}{$\begin{array}{c}\text { Weave } \\
\text { structure }\end{array}$} & \multicolumn{3}{|c}{ Color proportions (\%) } \\
\cline { 2 - 4 } & Warp & Weft & Background \\
\hline Plain & 54.55 & 19.77 & 25.68 \\
\hline $1 / 2$ twill & 51.34 & 22.85 & 25.81 \\
\hline $2 / 1$ twill & 47.29 & 26.47 & 26.24 \\
\hline $1 / 4$ sateen & 44.00 & 30.19 & 25.81 \\
\hline $4 / 1$ satin & 41.31 & 33.01 & 25.68 \\
\hline
\end{tabular}

del. In terms of $\mathrm{L}^{*}$ in $<$ Table $2>$, the colors of all samples were always predicted to be lighter than actual colors by $\log K / S$ model. Regarding $C^{*}$, the colors of all samples were predicted to have lower chroma values than those of actual colors. Further analysis revealed that the $\mathrm{C}^{*}$ differences are related to the weave structures. For a fabric with a higher proportion of weft color, i.e., red and blue, $\mathrm{C}^{*}$ difference will be higher compared to that of the fabric with a lower proportion of weft color.
The D-G model was found to be the second most accurate model for color prediction of woven fabrics. In particular, in terms of $\mathrm{L}^{*}$, the D-G model produced the most reasonable agreement between the measured and the predicted values with the average error of approximately equaling to 4.0 . The significantly lower error of $\mathrm{D}-\mathrm{G}$ model in prediction of $\mathrm{L}^{*}$ compared to other models also led to the lower $\Delta \mathrm{E}_{\mathrm{CMC}(2: 1)}$ values between the actual and the predicted colors.

The prediction results from W-O model generally showed the lowest $\triangle \mathrm{E}_{\mathrm{CMC}(2: 1)}$ values among six color mixing models with the range of 5.36 to 7.40 . In terms of $\mathrm{L}^{*}$, like $\log K / S$ model, the colors of all samples were predicted to be lighter than actual colors. Regarding $\mathrm{C}^{*}$, contrary to $\log K / S$ model, the sample colors were generally predicted to have higher chroma values than those of actual colors. Meanwhile, W-O model is a non-linear model while all other models have linear forms. The lowest average $\Delta \mathrm{E}_{\mathrm{CMC}(2: 1)}$ value of $\mathrm{W}-\mathrm{O}$ model indicates that a particularly strong non- 
Table 2. Measured and predicted colorimetric values of red woven fabrics

\begin{tabular}{|c|c|c|c|c|c|c|c|c|}
\hline \multirow[b]{2}{*}{ Specimen } & \multirow[b]{2}{*}{$\begin{array}{l}\text { Color } \\
\text { attributes }\end{array}$} & \multirow[b]{2}{*}{$\begin{array}{c}\text { Measured } \\
\text { value }\end{array}$} & \multicolumn{6}{|c|}{ Predicted values } \\
\hline & & & $\begin{array}{c}\text { Simple } K / S \\
\text { model }\end{array}$ & $\begin{array}{c}\log K / S \\
\text { model }\end{array}$ & $\begin{array}{c}\mathrm{D}-\mathrm{G} \\
\text { model }\end{array}$ & $\begin{array}{c}\mathrm{S}-\mathrm{N} \\
\text { model }\end{array}$ & $\begin{array}{c}\text { Modified } \\
\text { S-N model }\end{array}$ & $\begin{array}{c}\mathrm{W}-\mathrm{O} \\
\text { model }\end{array}$ \\
\hline \multirow{6}{*}{$\mathrm{W} \times \mathrm{R}-4 / 1 \mathrm{~S}$} & $\mathrm{~L}^{*}$ & 69.54 & 33.09 & 73.54 & 64.98 & 46.51 & 30.34 & 74.20 \\
\hline & $a^{*}$ & 14.65 & 8.18 & 9.57 & 11.61 & 12.27 & 7.18 & 24.66 \\
\hline & $\mathrm{b}^{*}$ & 4.11 & 2.31 & 5.77 & 8.03 & 4.98 & 1.54 & 11.03 \\
\hline & $\mathrm{C}^{*}$ & 15.21 & 8.50 & 11.17 & 14.12 & 13.24 & 7.34 & 27.01 \\
\hline & $\mathrm{h}$ & 15.67 & 15.64 & 30.96 & 34.61 & 22.29 & 11.86 & 24.23 \\
\hline & $\Delta \mathrm{E}_{\mathrm{CMC}(2: 1)}$ & & 22.11 & 5.06 & 5.29 & 11.22 & 25.32 & 6.81 \\
\hline \multirow{6}{*}{$\mathrm{W} \times \mathrm{R}-2 / 1 \mathrm{~T}$} & $\mathrm{~L}^{*}$ & 65.47 & 32.58 & 71.62 & 63.48 & 45.44 & 29.94 & 71.82 \\
\hline & $a^{*}$ & 16.85 & 8.97 & 11.71 & 13.42 & 13.69 & 7.78 & 27.86 \\
\hline & $\mathrm{b}^{*}$ & 4.81 & 2.63 & 6.57 & 9.12 & 5.64 & 1.79 & 12.56 \\
\hline & $\mathrm{C}^{*}$ & 17.52 & 9.35 & 13.43 & 16.23 & 14.81 & 7.98 & 30.56 \\
\hline & $\mathrm{h}$ & 15.94 & 16.17 & 29.25 & 34.22 & 22.29 & 12.95 & 24.23 \\
\hline & $\Delta \mathrm{E}_{\mathrm{CMC}(2: 1)}$ & & 20.62 & 7.30 & 4.86 & 10.08 & 23.79 & 7.24 \\
\hline \multirow{6}{*}{$\mathrm{W} \times \mathrm{R}-\mathrm{P}$} & $\mathrm{L}^{*}$ & 60.28 & 31.91 & 69.05 & 61.53 & 44.09 & 29.40 & 69.11 \\
\hline & $a^{*}$ & 20.37 & 9.72 & 14.50 & 15.56 & 15.17 & 8.32 & 31.50 \\
\hline & $\mathrm{b}^{*}$ & 6.28 & 2.98 & 7.63 & 10.39 & 6.35 & 2.04 & 14.42 \\
\hline & $\mathrm{C}^{*}$ & 21.32 & 10.17 & 16.38 & 18.71 & 16.45 & 8.57 & 34.64 \\
\hline & $\mathrm{h}$ & 17.12 & 17.22 & 27.92 & 33.82 & 22.78 & 14.04 & 24.70 \\
\hline & $\Delta \mathrm{E}_{\mathrm{CMC}(2: 1)}$ & & 19.30 & 5.64 & 5.21 & 8.91 & 22.55 & 7.40 \\
\hline \multirow{6}{*}{$\mathrm{W} \times \mathrm{R}-1 / 2 \mathrm{~T}$} & $\mathrm{~L}^{*}$ & 57.03 & 31.62 & 67.02 & 60.15 & 43.29 & 29.19 & 66.73 \\
\hline & $a^{*}$ & 28.22 & 10.62 & 17.25 & 17.74 & 16.86 & 9.07 & 34.70 \\
\hline & $\mathrm{b}^{*}$ & 11.15 & 3.42 & 8.71 & 11.72 & 7.20 & 2.37 & 16.18 \\
\hline & $\mathrm{C}^{*}$ & 30.34 & 11.16 & 19.32 & 21.26 & 18.33 & 9.37 & 38.29 \\
\hline & $\mathrm{h}$ & 21.55 & 17.74 & 26.57 & 33.42 & 23.27 & 14.57 & 25.17 \\
\hline & $\Delta \mathrm{E}_{\mathrm{CMC}(2: 1)}$ & & 21.62 & 8.23 & 7.16 & 10.28 & 25.25 & 5.36 \\
\hline \multirow{6}{*}{$\mathrm{W} \times \mathrm{R}-1 / 4 \mathrm{~S}$} & $\mathrm{~L}^{*}$ & 51.97 & 31.34 & 65.28 & 58.97 & 42.59 & 28.98 & 64.99 \\
\hline & $a^{*}$ & 39.68 & 11.25 & 19.49 & 19.40 & 18.03 & 9.55 & 37.02 \\
\hline & $\mathrm{b}^{*}$ & 19.33 & 3.71 & 9.62 & 12.72 & 7.81 & 2.60 & 17.55 \\
\hline & $\mathrm{C}^{*}$ & 44.14 & 11.85 & 21.73 & 23.20 & 19.65 & 9.90 & 40.97 \\
\hline & $\mathrm{h}$ & 25.97 & 18.26 & 26.10 & 33.42 & 23.27 & 15.11 & 25.17 \\
\hline & $\Delta \mathrm{E}_{\mathrm{CMC}(2: 1)}$ & & 28.10 & 14.10 & 12.72 & 15.79 & 32.40 & 5.43 \\
\hline
\end{tabular}

linear relationship between individual color components and the color mixture exists in color mixing for woven structures. This result will become an important guideline for developing new optimized color mixing models.

\section{Conclusions}

In this study, the color prediction of yarn-dyed woven fabrics was conducted by using six geometric- color mixing models. As a result, $\log K / S$ model, D$\mathrm{G}$ model, and W-O model were generally found to be more accurate in prediction of the final colors of the woven fabrics used. In particular, W-O model was the most accurate one with the least color difference between the measured and the predicted colors. The verified W-O model and its application to CAD systems is believed to increase the manufacturing efficiency in the creation of the desired color appearance of woven fabrics through the excellent color prediction of the 


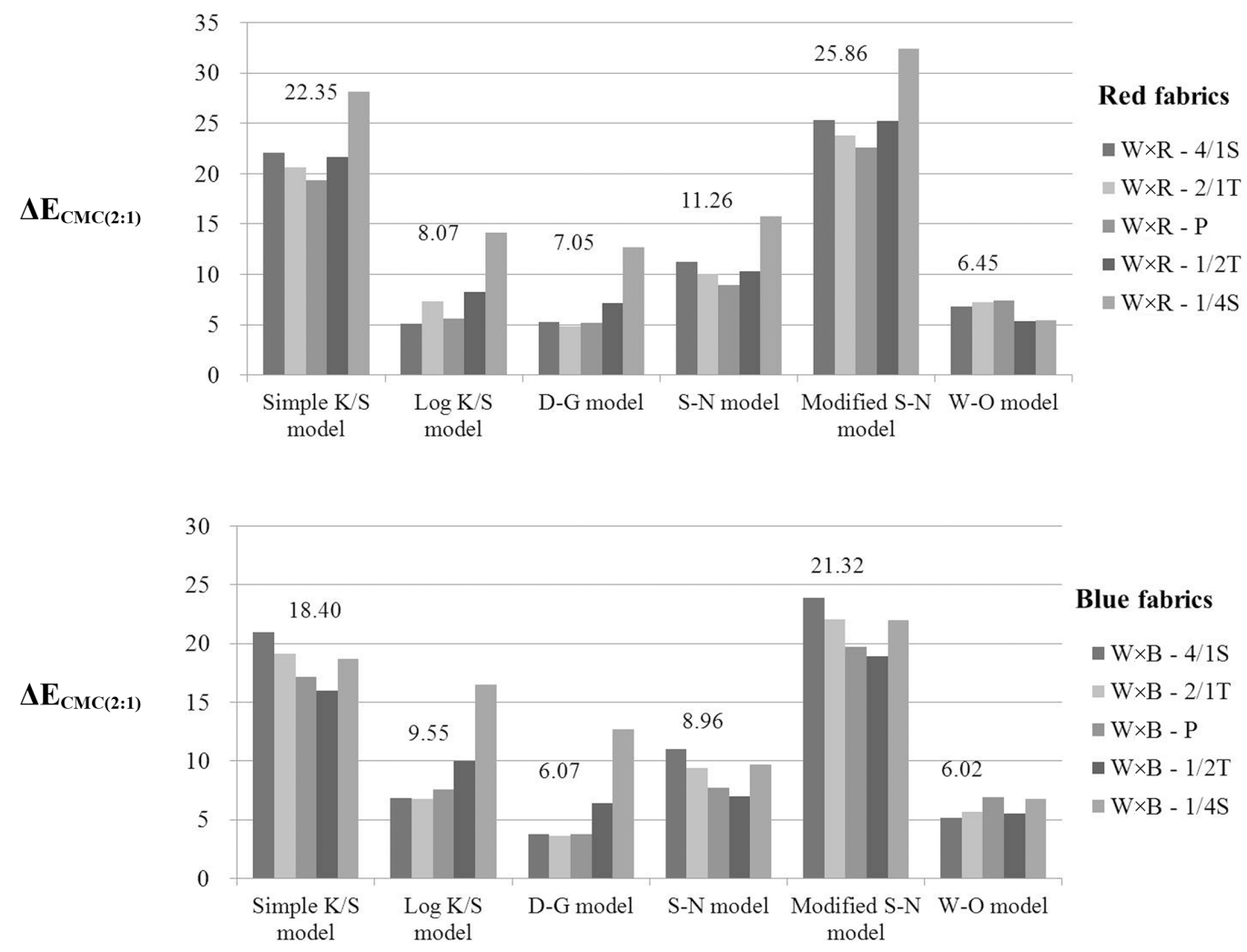

Fig. 3. $\Delta \mathrm{E}_{\mathrm{CMC}(2: 1)}$ between measured and predicted values of six color mixing models.

simulation and thereby reduced physical sampling which is obviously time and money consuming.

Further study will be done to determine the detailed theoretical basis of why W-O model performs best by using mechanically, geometrically, and colorimetrically various samples. In addition, there was a tendency that the three best models, i.e. $\log K / S$ model, DG model, and W-O model, predicted colors more brightly than their actual colors. This tendency is thought to be due to no consideration of shadows imposed by threedimensional structures of woven fabrics. In the future study, the current color models will be optimized by considering geometric factors of woven structures to improve their performance in color prediction.

\section{References}

Burlone, D. A. (1984). Theoretical and practical aspects of selected fiber-blend color formulation functions. Color
Research and Application, 9(4), 213-219.

Dimitrovski, K., \& Gabrijelcic, H. (2004). Corrections of color values of woven fabrics using changes to constructional parameters. AUTEX Research Journal, 4(4), 187193.

Mathur, K. (2007). Color prediction model for jacquard tapestry woven fabrics. Unpublished doctoral dissertation, North Carolina State University, Raleigh.

Mathur, K., Hinks, D., Seyam, A. M., \& Donaldson, R. A. (2009). Towards automation of color/weave selection in jacquard design: model verification. Color Research and Application, 34(3), 225-232.

Philips-Invernizzi, B., Dupont, D., Jolly-Desodt, A. M., \& Cazé, C. (2002). Color formulation by fiber blending using the Stearns-Noechel model. Color Research and Application, 27(2), 100-107.

Reed, J., Jasper, W., \& Hinks, D. (2004). Quantitative measurement of web uniformity of blended fibers. Paper presented at the International Nonwovens Technical Conference, Toronto.

Seyam, M. A. F., \& Mathur, K. (2012). A general geometrical model for predicting color mixing of woven fabrics 
from colored warp and filling yarns. Fibers and Polymers, 13(6), 795-801.

Stearns, E. I., \& Noechel, F. (1944). Spectrophotometric prediction of color of wool blends. American Dyestuff Reporter, 33(9), 177-180.
Warburton, P., \& Oliver, P. (1956). Colour and textiles IVThe blending of coloured fibres. Journal of the Textile Institute Proceedings, 47(5), 361-373. doi:10.1080/1944 7015608665257 